\title{
ZNAČAJ POTPORE PARTNERA PRI PORODAJU U RODILIŠTU SVEUČILIŠNE KLINIČKE BOLNICE MOSTAR
}

\author{
Katarina Vidakušić, Olivera Perić, Vajdana Tomić, Nikolina Soeken, Matija Kajić-Mikulić \\ Sveučilišna klinička bolnica Mostar, Klinika za ginekologiju i porodništvo. \\ Rad je primljen 17.4.2016. \\ Rad je korigiran 21.4.2016. \\ Rad je prihvaćen 22.4.2016
}

\section{SAŽETAK}

CILJ RADA: Ispitati postoje li razlike u očekivanju od porođaja i razini anksioznosti kod trudnica koje su imale potporu od strane partnera tijekom porođaja u odnosu na kontrolnu skupinu.

METODE: Razlike u očekivanju od porođaja i razini anksioznosti kod trudnica ispitane su putem anonimnog upitnika. U istraživanje je bilo uključeno 40 trudnica u trećem trimestru uredne trudnoće. Istraživanje je provedeno na Klinici za ginekologiju i porodništvo Sveučilišne kliničke bolnice Mostar u razdoblju od 20. ožujka do 20. svibnja 2015. godine.

REZULTATI: Ispitanice iz skupine trudnica koje su imale potporu partnera tijekom porođaja imale su statistički značajno veći osjećaj sigurnosti ( $t$-test za nezavisne uzorke; $\mathrm{p}=0,032$ ), u odnosu na ispitanice iz kontrolne skupine. Ispitanice iz ispitivane skupine imale su i manji osjećaj straha $(\mathrm{p}=0,032)$, manji osjećaj napetosti $(\mathrm{p}=0,007)$ i bolji osjećaj kontrole mogućih bolova tijekom porođaja $(\mathrm{p}=0,039)$. Ispitanice koje su imale potporu od strane partnera tijekom porođaja pokazale su bolje rezultate u osjećaju smirenosti ( $\mathrm{p}=0,024)$, te u osjećaju opuštenosti $(\mathrm{p}=0,032)$.

ZAKLJUČAK: Trudnice koje su imale potporu partnera tijekom porođaja imaju statistički značajno veći osjećaj sigurnosti, manji osjećaj straha i napetosti u odnosu na trudnice koje nisu imale istu podršku.

Ključne riječi: porođaj, očekivanja, potpora partnera.

Osoba za razmjenu informacija:

Bacc. ses. Vidakušić Katarina

e-mail: katarina04@outlook.com

\section{UVOD}

Trudnoća i porođaj uvode sa sobom brojne biološke, psihološke i društvene promjene koje zahtijevaju rješenja i prilagodbu majki. Sve te promjene i poteškoće prilagodbe s kojima se suočava buduća majka čine vrijeme porođaja vremenom ogromnog stresa za mnoge žene, posebno one koje ranije nisu prolazile nikakve pripreme za taj događaj.

Davno su prošla vremena kada su očevi bili prepušteni iščekivanju najave o rođenju vlastitog djeteta od strane liječnika i medicinskih sestara. Umjesto toga, sada više nego ikada otac igra aktivnu ulogu u rođenju djeteta.

U usporedbi s uobičajenom skrbi, pružanje kontinuirane potpore ženama tijekom porođaja povećava vjerojatnost spontanog vaginalnog porođaja, smanjuje trajanje porođaja, primjenu analgezije, učestalost carskog reza i instrumentalno dovršenje vaginalnog porođaja. Manje djeca je rođeno s niskim
Apgar rezultatom nakon pet minuta, a majke izražavaju veće zadovoljstvo s iskustvom rađanja (1).

Negativna iskustva na porođaju povećavaju rizik nastanka postporođajne depresije, a mogu negativno utjecati na stavove prema budućim trudnoćama i porodima te može potaknuti žene da zatraže carski rez (2). Dakle, poznavanje čimbenika koji utječu na majčino zadovoljstvo je važno kako bi se poboljšala skrb u porođaju.

Cilj ovog istraživanja je ispitati postoje li razlike u očekivanju od porođaja i razini anksioznosti kod trudnica koje su imale potporu od strane partnera tijekom porođaja u odnosu na kontrolnu skupinu.

\section{Ispitanici i metode}

Provedeno je prospektivno randomizirano istraživanje u skupini trudnica na Klinici za ginekologiju i porodništvo Sveučilišne kliničke bolnice Mostar u 
razdoblju od 20. ožujka do 20. svibnja 2015. godine. U istraživanje je bilo uključeno 40 trudnica u trećem trimestru uredne trudnoće koje su u navedenom razdoblju dolazile na redoviti ginekološki pregled, a zadovoljavale su kriterij trećeg trimestra. Kod svih ispitanica očekivao se spontani vaginalni porođaj. Trudnice s prethodnim pobačajima i patologijom trudnoće isključene su iz studije. Trudnice su podijeljene u dvije skupine. Ispitivanu skupinu činilo je 20 trudnica koje su tijekom porođaja imale potporu od strane svojih partnera. Kontrolnu skupinu činilo je 20 trudnica koje nisu tijekom porođaja imale potporu od strane svojih partnera.

U istraživanju su korištena dva upitnika: „Childbirth Expectations Questionnaire“ (CEQ) prije porođaja (3) i „Beck Anxiety Inventory“ (4) nakon porođaja. Prvi dio CEQ upitnika je sadržavao socio-demografska pitanja, a drugi dio upitnika kojim je ispitivan stav trudnice prema porođaju sastojao se od 37 tvrdnji pri čemu su ispitanice svakoj posebno pridružile po jedan broj od 1 do 5 , ovisno o tome koliko se „slažu“ odnosno „ne slažu“ s navedenom tvrdnjom. Broj 5 označava potpuno slaganje s ponuđenom tvrdnjom dok broj 1 označava potpuno neslaganje s navedenim. Od ukupnih 37 tvrdnji upitnik sadrži 17 negativnih tvrdnji koje su zahtijevale obrnuto bodovanje i zbrajanje. Maksimalan broj bodova u upitniku je 185 . Trudnice koje su odgovorile na upitnik s 120-185 bodova imaju pozitivne i umjereno pozitivne stavove, a one koje su imale manje od 120 bodova imaju negativne stavove prema porođaju.

Backov upitnik anksioznosti mjeri trenutno stanje anksioznosti. Upitnik se sastoji od dvadeset $\mathrm{i}$ jedne tvrdnje kojima ispitanica treba pridružiti brojeve od 0 do 3, ovisno o stupnju slaganja s istom. Teorijski najmanji mogući indeks anksioznosti može biti 0, a najveći 63. Rezultati upitnika se klasificiraju u četiri skupine:

- minimalno anksiozne (neanksiozne) koje su imale zbroj od 0-9

- blago anksiozne koje su imale zbroj od 10-16

- umjereno anksiozne koje su imale zbroj od 17-29

- teže anksiozne koje su imale zbroj od 30-63.

Prije same primjene upitnika ispitanicama je rečeno kako se ispituju očekivanja od porođaja i razina anksioznosti nakon porođaja, te je detaljnije objašnjen cilj istraživanja. Naglašeno je kako je ispitivanje anonimno i kako će se rezultati koristiti isključivo $\mathrm{u}$ istraživačke svrhe. Ispitanice koje su prihvatile sudjelovati u istraživanju dobile su upitnik koju su ispunjavale samostalno.

Simetričnost varijabli testirana je Kolmogorov-Smirnov testom. Raspodjela kontinuiranih podataka bila je simetrična, te smo za prikaz srednje vrijednosti i mjere raspršenja koristili aritmetičku sredinu i standardnu devijaciju. Pri usporedbi kontinuiranih varijabli, zbog simetričnosti podataka, korišten je T-test za nezavisne uzorke. Za razliku razdioba nominalnih i ordinarnih varijabli korišten je hi-kvadrat test. Za statističku analizu rabljen je programski sustav SPSS for Windows (inačica 13.0, SPSS Inc, Chicago, Illinois, SAD) i Microsoft Excell (inačica 11. Microsoft Corporation, Redmond, WA, SAD).

\section{Rezultati}

U sveukupnim očekivanjima od porođaja ispitanice iz skupine trudnica koje su imale potporu partnera tijekom porođaja imale su statistički značajno veći osjećaj sigurnosti (t-test za nezavisne uzorke; $\mathrm{p}=0,032)$, $\mathrm{u}$ odnosu na ispitanice iz kontrolne skupine. Kod ostalih pitanja vezanih za sveukupna očekivanja od porođaja nije pronađena statistički značajna razlika (t-test za nezavisne uzorke) (Tablica 1 ).

Tablica 1. Prikaz razlika u sveukupnim očekivanjima od porođaja izmedu trudnica koje su imale potporu od strane partnere tijekom porođaja i onih koje nisu imale istu podršku

\begin{tabular}{lccc}
\hline \multirow{2}{*}{ Trrdnja } & \multicolumn{2}{c}{ Broj bodova koje su ispitanice dale za pojedini odgovor. } & \\
\cline { 2 - 3 } & \multicolumn{1}{c}{ Ispitivana skupina } & Kontrolna skupina & \multirow{2}{*}{ * $^{*}$} \\
\cline { 2 - 3 } & M-SD & M-SD & \\
\hline Divan & $3,25-1,10$ & $3,35-1,38$ & 0,750 \\
Zastrǎsujući & $3,70-0,98$ & $4,12-0,95$ & 0,091 \\
Normalan & $4,32-0,74$ & $4,23-0,90$ & 0,662 \\
Produljen & $3,32-0,95$ & $3,69-0,97$ & 0,121 \\
Pretežak & $3,64-1,01$ & $3,92-1,05$ & 0,264 \\
Siguran & $4,46-0,95$ & $3,58-0,95$ & 0,032 \\
Bolan & $2,43-0,92$ & $2,69-1,19$ & 0,311 \\
\hline
\end{tabular}

${ }^{*}$ t test za nezavisne uzorke 
Obrađeni su podatci koji se odnose na očekivanja ispitanica o tome što će osjećati tijekom trajanja trudova. Ispitanice iz ispitivane skupine imale su manji osjećaj straha koji su ocijenile s 2,52 $( \pm 1,08)$ boda u odnosu na ispitanice iz kontrolne koje su strah ocijenile s 3,15 $( \pm 1,28)$ boda, što je također činilo statistički značajnu razliku (t-test za nezavisne uzorke; $\mathrm{p}=0,032$ ). Ispitanice iz ispitivane skupine osjećaj sigurnosti tijekom porođaja ocijenile su $\mathrm{s}$ $3,95( \pm 0,83)$, dok su ispitanice iz kontrolne skupine isti osjećaj ocijenile s $2,88( \pm 0,94)$ što se pokazalo statistički značajno (t-test za nezavisne uzorke; $\mathrm{p}=0,017)$. Ispitanice iz ispitivane skupine istaknule su osjećaj napetosti ocijenivši ga s 2,20 $( \pm 0,82)$ boda, dok su ispitanice iz kontrolne skupine napetost ocijenile s 2,85 $( \pm 1,08)$ boda, što je činilo statistički značajnu razliku (t-test za nezavisne uzorke; $\mathrm{p}=0,007$ ). (Tablica 2).

Tablica 2. Prikaz razlika u očekivanjima trudnica koje su imale potporu od strane partnera tijekom porođaja i onih koje nisu imale istu podršku za vrijeme trajanja trudova.

\begin{tabular}{|c|c|c|c|}
\hline \multirow{3}{*}{ Tvrdnja } & \multicolumn{2}{|c|}{$\begin{array}{c}\text { Broj bodova koje su ispitanice dale } \\
\text { za pojedini odgovor. }\end{array}$} & \multirow{3}{*}{$p^{*}$} \\
\hline & Ispitivana skupina & Kontrolna skupina & \\
\hline & M-SD & M-SD & \\
\hline Iznenađeno & $3,52-1,11$ & $3,23-1,10$ & 0,291 \\
\hline Usamljeno & $3,80-1,13$ & $3,81-1,16$ & 0,966 \\
\hline Jako & $3,16-1,05$ & $3,46-1,14$ & 0,265 \\
\hline Samopouzdano & $3,27-1,06$ & $3,58-0,90$ & 0,227 \\
\hline Uplašeno & $2,52-1,08$ & $3,15-1,28$ & 0,032 \\
\hline Jako slabo & $3,55-0,87$ & $3,77-0,99$ & 0,329 \\
\hline Vrlo sigurno & $3,95-0,83$ & $2,88-0,94$ & 0,017 \\
\hline Neovisno & $3,02-0,82$ & $3,15-0,92$ & 0,540 \\
\hline Potišteno & $3,48-0,92$ & $3,73-1,04$ & 0,295 \\
\hline Napeto & $2,20-0,82$ & $2,85-1,08$ & 0,007 \\
\hline Ushićeno & $3,77-0,91$ & $3,85-0,88$ & 0,743 \\
\hline Ponosno & $4,07-0,95$ & $4,23-0,76$ & 0,461 \\
\hline Predat ću se & $4,30-0,87$ & $3,85-1,04$ & 0,058 \\
\hline Bit ću tiha & $2,98-1,08$ & $3,04-1,11$ & 0,822 \\
\hline 0puštena & $2,80-1,06$ & $3,00-1,16$ & 0,457 \\
\hline Bolno & $2,34-0,96$ & $2,65-0,97$ & 0,196 \\
\hline Vezat ću se za bebu & $4,48-0,64$ & $4,65-0,68$ & 0,293 \\
\hline
\end{tabular}

$*_{t}$ test za nezavisne uzorke
Analizirajući očekivanja kako će se ispitanice ponašati za vrijeme pojačavanja trudova, utvrđena je statistički značajna razlika u toleriranju bolova. Naime, ispitanice iz ispitivane skupine osjećaj toleriranja bolova tijekom porođaja ocijenile su $\mathrm{s}$ $3,95( \pm 0,90)$, dok su ispitanice iz kontrolne skupine isti osjećaj ocijenile s 2,28 $( \pm 1,09)$ što se pokazalo statistički značajno ( $\mathrm{t}$-test za nezavisne uzorke; $\mathrm{p}=0,039)$. Ostale tvrdnje nisu pokazale statistički značajnu razliku.

Raščlambom rezultata dobivenih upitnikom BAI (Back Anxiety Inventory) pokazala se statistički značajna razlika u dvjema varijablama u upitniku u korist ispitanica iz ispitivane skupine. Naime ispitanice koje su imale potporu od strane partnere tijekom porođaja pokazale su statistički značajno bolje rezultate u osjećaju smirenosti ( $\mathrm{t}$-test za nezavisne uzorke; $\mathrm{p}=0,024)$ te $\mathrm{u}$ osjećaju opuštenosti ( $\mathrm{t}$-test za nezavisne uzorke; $\mathrm{p}=0,032$ ).

\section{RASPRAVA}

U svjetskoj literaturi postoje različiti rezultati ovakvih studija; raspon očekivanja se kreće od pozitivnih (5) do uglavnom negativnih očekivanja od porođaja (6). Ispitanice iz skupine trudnica koje su imale potporu partnera tijekom porođaja imale su statistički značajno veći osjećaj sigurnosti tijekom porođaja u odnosu na ispitanice iz kontrolne skupine. Također trudnice koje su imale potporu partnera tijekom porođaja imale su i manji osjećaj straha i napetosti tijekom porođaja. Slični rezultati navode se i u literaturi, tj. povezanost prisutnosti partnera koji pruža potporu sa znatnim skraćenjem trajanja porođaja, smanjenom potrebom za oksitocinskom terapijom, manjim brojem carskih rezova te instrumentalnog dovršenja porođaja. U studiji provedenoj u Sjedinjenim Državama, skupina s potporom uspoređivana je s dvjema kontrolnim skupinama: jednom u kojoj je bio prisutan neaktivni partner te drugom, koja je primila uobičajenu bolničku skrb. Rezultati pokazuju bolje opstetričke i neonatalne ishode skupine s potporom $\mathrm{u}$ odnosu na skupinu $\mathrm{s}$ neaktivnim partnerom, ali i skupine s neaktivnim partnerom u odnosu na skupinu koja je primila uobičajenu bolničku skrb (7). 
Također, rezultati ovog istraživanja su pokazali značajnu razliku među ispitanicama u nekim varijablama crta anksioznosti. Ispitanice iz skupine trudnica koje su imale potporu partnera tijekom porođaja bile su statistički značajno smirenije i opuštenije.

Dokazano je da ljepša očekivanja pomažu trudnicama da vjeruju u sebe i ponašaju se na pozitivan način dok negativna očekivanja dovode do sloma osjećaja i nezadovoljstva vezanog za porođaj (8). Rad na prije porođajnim pripremama pomaže ženama da dožive ugodnija porođajna iskustva i umanje strah i nervozu koju povezuju sa svojim porođajem (9).

\section{LITERATURA}

1. Amorim MMR, Katz L. Continuous support for women during childbirth: RHL commentary. The WHO Reproductive Health Library; Geneva: World Health Organization.

2. Pang MW, Leung TN, Lau TK, Hang Chung TK. Impact of first childbirth on changes in women's preference for mode of delivery: followup of a longitudinal observational study. Birth. 2008;35:121-128.

3. Dencker A, Bergqvist L, Håkan L, Berg M. Childbirth experience questionnaire (CEQ): deve- lopment and evaluation of a multidimensional instrument BMC Pregnancy and Childbirth. 2010;10:81.

4. Michael M. Grant. Beck Anxiety Inventory (Internet) Dostupno na: https://Beck_Anxiety_ Inventory_explanation\%20(1).pdf (pristupljeno 14. 06. 2015).

5. Waldenstrom U, Borg MI, Olsson B, Skold M, Wall S. The childbirth experience: A study of 295 new mothers. Birth. 1996;23:144-53.

6. Wijma K, Soderquist J, Wijma B. Post-traumatic stress disorder after childbirth: A cross sectional study. J Anxiety Disord. 1997;11:587-97.

7. Bester MB, Nolte AG. Knowledge and expectations of childbirth in primigravidas. Curationis. 2002;15:12-5.

8. Waldenstrom U, Hildingsson I, Ryding EL. Antenatal fear of childbirth and its association with subsequent caesarean section and experience of childbirth. BJOG. 2006;113:638-46.

9. Green J.M, Coupland V.A \& Kitzinger J.V. Expectations, experiences, and psychological outcomes of childbirth: a prospective study of 825 women. Birth. 1990;17:15-24. 


\title{
IMPORTANCE OF PARTNERS AT BIRTH IN THE MATERNITY WARDS OF THE UNIVERSITY CLINICAL HOSPITAL IN MOSTAR
}

\author{
Vidakušić Katarina, Perić Olivera, Tomić Vajdana, Soeken Nikolina, Kajić-Mikulić Matija \\ University Clinical Hospital Mostar, Department of Obstetrics and Gynaecology \\ 88000 Mostar, Bosnia and Herzegovina
}

\begin{abstract}
INTRODUCTION: Throughout history partner presence during childbirth was unwanted but in recent years they were given an opportunity to support and participate during labour.

OBJECTIVE: The objective of this study was to measure the level of anxiety in pregnant women who have had the support of their birth partner during labour compared to the control group.

METHODS: Differences in anticipation of giving birth and the level of anxiety in pregnant women were tested by means of an anonymous questionnaire. The study was conducted at the Department of Obstetrics and Gynaecology of the University Clinical Hospital in Mostar during the period from March 20 to May 20, 2015. The study included 40 pregnant women in the third trimester of their pregnancy.

RESULTS: The group of pregnant women who had the support of their birth partners during labour had a significantly greater sense of security ( $\mathrm{t}$-test for independent samples; $\mathrm{p}=0.032$ ), as opposed to women in the control group. The subjects of the test group had a smaller sense of fear $(p=0.032)$, lower anxiety $(p=0.007)$ and a better sense of pain control during labour and delivery $(\mathrm{p}=0.039)$. Subjects who had the support of their birth partner during labour shown better results in the sense of security $(p=0.024)$, and in the sense of relaxation $(p=0.032)$.
\end{abstract}

CONCLUSION: Pregnant women who had the support of their birth partner during labour had a significantly higher sense of security, and lower anxiety level, as opposed to women who did not have the same support.

Keywords: birth, expectations, birth partners

Correspondence:

Vidakušić Katarina, BA

e-mail: katarina04@outlook.com 